\title{
Article \\ Experimental and Numerical Analysis of Wave Drift Force on KVLCC2 Moving in Oblique Waves
}

\author{
Min Guk Seo ${ }^{1}$, Yoon Jin Ha ${ }^{1}$, Bo Woo Nam ${ }^{2, *}$ and Yeongyu Kim ${ }^{1}$ \\ 1 Korea Research Institute of Ships and Ocean Engineering, Daejeon 34103, Korea; mgseo@kriso.re.kr (M.G.S.); \\ yj_ha0811@kriso.re.kr (Y.J.H.); ygkim@kriso.re.kr (Y.K.) \\ 2 Department of Naval Architecture and Ocean Engineering, Seoul National University, Seoul 08826, Korea \\ * Correspondence: bwnam@snu.ac.kr
}

\section{check for} updates

Citation: Seo, M.G.; Ha, Y.J.; Nam, B.W.; Kim, Y. Experimental and Numerical Analysis of Wave Drift Force on KVLCC2 Moving in Oblique Waves. J. Mar. Sci. Eng. 2021, 9, 136. https://doi.org/10.3390/jmse9020136

Received: 30 December 2020

Accepted: 22 January 2021

Published: 29 January 202

Publisher's Note: MDPI stays neutral with regard to jurisdictional claims in published maps and institutional affiliations.

Copyright: (C) 2021 by the authors Licensee MDPI, Basel, Switzerland. This article is an open access article distributed under the terms and conditions of the Creative Commons Attribution (CC BY) license (https:// creativecommons.org/licenses/by/ $4.0 /)$

\begin{abstract}
In this study, experimental and numerical methods were applied to estimate surge and sway wave drift forces and yaw drift moment acting on KVLCC2, advancing in oblique wave. An experiment was carried out in the ocean engineering basin of the Korea Research Institute of Ships and Ocean Engineering (KRISO). A series of regular wave tests under various heading conditions were conducted to investigate ship motion responses and wave drift forces. A Rankine panel method based on potential flow was adopted in the numerical analysis, and the direct pressure integration method that integrates second-order pressure on the hull surface was applied to compute wave drift force. Through this study, validation data of wave drift force acting on KVLCC2 was established, and the computation capability of the potential-based numerical method was systematically analyzed.
\end{abstract}

Keywords: wave drift force; oblique wave; KVLCC2; model test; Rankine panel method

\section{Introduction}

The energy efficient design index (EEDI) was recently proposed by the International Maritime Organization (IMO) to restrict greenhouse gas emissions from sailing ships, as required by the IMO mandatory regulation since 2013 [1]. EEDI is intended to identify the characteristics of $\mathrm{CO}_{2}$ emission according to the vessel type and size and calculate the expected $\mathrm{CO}_{2}$ emission for newly built vessels. The estimated $\mathrm{CO}_{2}$ emission should be below the reference line according to the regulatory standard. The EEDI regulation has been strengthened over time, and various efforts have been made to satisfy it. One of the most effective ways to satisfy the EEDI regulation is slow steaming, which can reduce $\mathrm{CO}_{2}$ emissions as well as fuel consumption. However, slow steaming has serious issues such as longer time to transport the cargo, adverse effects on the engine, and concerns regarding the stability of a new vessel equipped with a small engine. In particular, stability issues of vessels with a small engine are frequently reported, and the Marine Environment Protection Committee (MEPC) of the IMO has proposed a guideline for minimum propulsion power to maintain the maneuverability of ships under adverse conditions [2]. In this regard, various studies on the performance of ships in waves have been actively conducted, mainly by JASNAOE (the Japan Society of Naval Architects and Ocean Engineers) in Japan, SHOPERA (Energy Efficient Safe Ship Operation) in the EU, and an R\&D project of KRISO (Korea Research Institute of Ships and Ocean Engineering) in Korea [3-8]. It is essential to evaluate the ship performance in waves, and the accurate estimation of the wave drift force on the advancing ship is considered increasingly important.

In general, the surge wave drift force on an advancing ship is termed added resistance because it is an additional resistance due to waves. Since the 1960s, this added resistance problem has been widely studied, primarily using a potential-based numerical method. Maruo [9] introduced the momentum conservation method, called the far-field method, and it was further developed by Newman [10]. Faltinsen et al. [11] applied the direct pressure integration method (near-field method), where the added resistance is calculated by 
integrating the second-order pressure on the hull surface. At this time, these methods were mainly applied to the 2D strip method. With an improvement in computers' processing capacity, the 3D panel method has also been applied to compute the added resistance. Bunnik [12] used the Rankine panel method to calculate the added resistance in waves and investigated the variation in the results according to the linearization scheme (uniform flow, double-body flow, nonlinear flow). Zhang et al. [13] used the time domain Rankine panel method to calculate the added resistance on a moving ship. Linear and body nonlinear schemes were applied and the results of each scheme were compared. Jonquez [14] and Kim et al. [15] also adopted the higher-order Rankine panel method to calculate added resistance and applied both far- and near-field methods in the Rankine panel method. The research group at Seoul National University performed various studies using the Rankine panel method. In-depth research has been conducted on various aspects by confirming the parameters that can affect the added resistance, such as parametric roll, internal sloshing flow, ship draft, and ship flexibility [16-19]. Seo et al. [20] applied two numerical methods (Rankine panel method and Cartesian grid method) to confirm the computation capability for added resistance at short wavelengths. In addition, the established asymptotic methods based on short wavelengths were examined.

Martic et al. [21] calculated the added resistance on KCS by applying the 3D panel method based on the Kelvin-type Green function. The added resistance in short-wavelength was compensated using the National Maritime Research Institute (NMRI) method (Kuroda et al. [22] and Tsujimoto et al. [23]), and a sensitivity study of added resistance according to prismatic coefficient, longitudinal center of buoyancy, trim, pitch gyration, and ship speed was conducted. Yang et al. [24] applied the Cartesian-grid method to analyze the added resistance on the modified Wigley hull. Added resistance was derived using the direct pressure integration method and unsteady wave analysis (Kashiwagi [25]). The influence of the measurement point of the unsteady wave on the added resistance was examined. Liu and Papanikolaou [26] presented an empirical formula for added resistance that can be applied at arbitrary wavelength, heading, and draft. To this end, about 130 ships and 3000 added resistance data were collected. The diffracted effect was reflected by updating the existing asymptotic formula (Faltinsen et al. [11]), and the radiation effect improved the empirical formula of Jinkine and Ferdinande [27].

An experiment is one of the most reliable methods to measure the wave drift force. Since the 1970s, the added resistance has been widely studied by conducting model tests. Storm-Tejsen et al. [28] measured the added resistance on a Series 60 parent hull and identified the characteristics of the added resistance. The added resistance on S175 with various ship speeds was measured by Fujii and Takahashi [29] and Nakamura and Naito [30]. KCS and KVLCC2, which are publicly released hulls by KRISO, have been widely used in experiments. Guo and Steen [31] and Sadat-Hosseini et al. [32] conducted model tests for the added resistance on KVLCC2, and Park et al. [33] performed an uncertainty analysis on the results of the added resistance experiment on KVLCC2. Lee et al. [34] conducted a series of experiments by changing the bow shape of KVLCC2, and examined the effects of different bow shapes on the added resistance. Joncquez [35] and Simonsen et al. [36] conducted model tests on the added resistance on KCS. The experimental values of the added resistance under the oblique sea conditions were lower than those under the head sea condition. In particular, experiments that measured not only the surge wave drift force (added resistance) but also the sway and yaw wave drift force and moment on an advancing ship are uncommon. Park et al. [37] conducted experiments under the oblique sea condition to measure the added resistance on a tanker. The self-propulsion test was adopted, and wave direction was modified in intervals of $30^{\circ}$ from 180 to $0^{\circ}$. In the $\mathrm{SH}-$ OPERA project, DTC and ROPAX with zero and low forward speeds were used to measure the 3-degrees of freedom (DOF) wave drift forces (surge, sway, and yaw wave drift forces and moments). KVLCC2 with zero forward speed was also used to measure the wave drift force (Sprenger and Fathi [5], Maron [6]). 
In this study, the wave drift force acting on an advancing KVLCC2 was evaluated by experimental and numerical methods. In the experiment, a 1/100 scale model was used, and a series of model tests were performed with a soft spring type mooring system in the ocean engineering basin (OEB) of KRISO. Experiments were conducted at two different speeds and various wave conditions. To estimate the wave drift force in the experiment, two different measurement methods were used-a direct method using force sensors, and an indirect method using tensiometers. The results of each method were summarized and compared. The potential-based Rankine panel method was used for the numerical analysis, and the direct pressure integration method was adopted to estimate the wave drift force on a ship. Through this study, the data of the wave drift force acting on KVLCC2 were validated and the computation capability of the potential-based numerical method was systematically analyzed.

\section{Model Test}

\subsection{Experimental Model}

A series of model tests were conducted to evaluate the wave drift force acting on a KVLCC2 model in the ocean engineering basin of KRISO. The primary purpose of the model test was to establish the validation data set of the wave drift forces under various wave heading conditions. The 1/100 scaled model of KVLCC2, as shown in Figure 1, was made of fiber-reinforced plastic (FRP). Only the bare hull was considered without the propeller and rudder system. The main dimensions of the KVLCC2 model are summarized in Table 1.

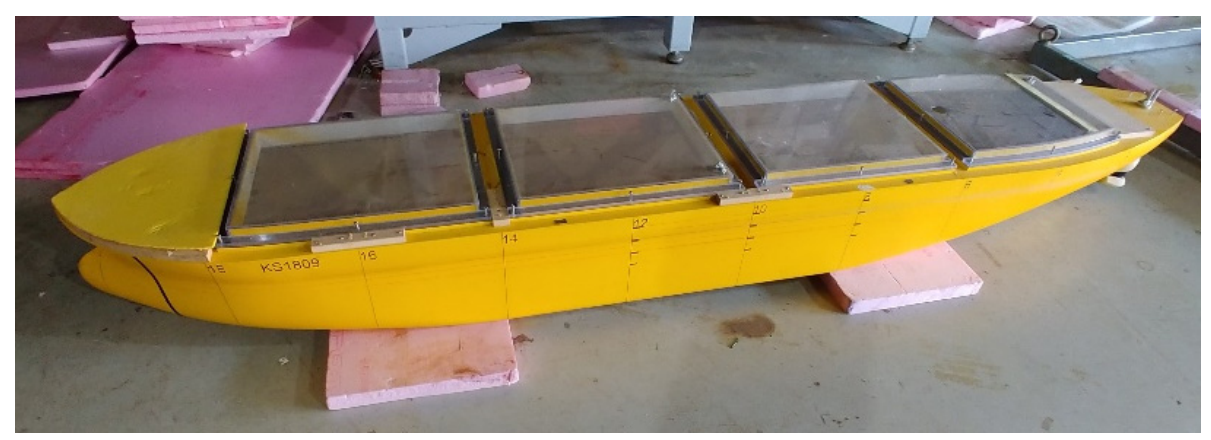

Figure 1. Experimental model of KVLCC2.

Table 1. Main dimensions of KVLCC2.

\begin{tabular}{cccc}
\hline Item & Unit & Proto & Model \\
\hline Scale ratio & {$[-]$} & 1 & $1 / 100$ \\
Length & {$[\mathrm{m}]$} & 320.0 & 3.200 \\
Breadth & {$[\mathrm{m}]$} & 58.0 & 0.580 \\
Draft & {$[\mathrm{m}]$} & 20.8 & 0.208 \\
Displacement volume & {$\left[\mathrm{m}^{3}\right]$} & $312,622.0$ & 0.313 \\
Longitudinal center of gravity from midship & {$[\mathrm{m}]$} & 11.1 & 0.111 \\
Metacentric height & {$[\mathrm{m}]$} & 5.8 & 0.058 \\
Longitudinal gyration & {$[-]$} & 0.239 & 0.239 \\
(kyy/L) & {$[\mathrm{sec}]$} & 17.3 & 1.730 \\
Roll period & & &
\end{tabular}

\subsection{Test Conditions}

The test cases presented in Table 2 were selected to examine the effects of wave conditions and ship speed on the wave drift force. The wave direction was selected in $30^{\circ}$ intervals from the head sea condition $\left(180^{\circ}\right)$ to the following sea condition $\left(0^{\circ}\right)$. In the KRISO OEB, the wavemaker was arranged both north side and east side. The oblique wave could then be generated using both side wavemakers. However, in this study, 
the oblique wave using both side wavemakers was not applied, and only perpendicular directional waves were used. The ship was then towed obliquely to realize the bow and stern quartering wave condition, as shown in Figure 2. The wavelengths were non-equally spaced from $\lambda / L=0.5$ to 1.5 . The ship speeds were selected as 15.5 knots (design speed of KVLCC2) and 6 knots (steady turning speed during the turning test with $35^{\circ}$ rudder angle). For both ship speeds, experiments were conducted for all wave conditions given in Table 2.

As shown in Figure 2, the length and width of the basin were 56 and $30 \mathrm{~m}$, respectively, and the depth was $4.5 \mathrm{~m}$. The water depth was $3.2 \mathrm{~m}$. Piston type wavemakers were installed along the long and short sides, and wave absorption beaches were located on the opposite sides. The towing carriage could move simultaneously in the $\mathrm{X}$ and $\mathrm{Y}$ directions, thus realizing oblique motion.

Table 2. Test cases of model test.

\begin{tabular}{ccc}
\hline Item & Case & \# of Case \\
\hline Wave direction, $\beta[\mathrm{deg}]$ & $180,150,120,90,60,30,0$ & 7 \\
Wave length $(\lambda / \mathrm{L})$ & $0.5,0.7,0.85,1.0,1.1,1.2,1.5$ & 7 \\
Wave height, $\mathrm{h}[\mathrm{m}]$ & $6.4(\mathrm{H} / \mathrm{L}=1 / 50)$ & 1 \\
Ship speed $[\mathrm{knots}]$ & $15.5,6.0$ & 2 \\
\hline \multicolumn{2}{c}{ Total Cases } & 98 \\
\hline
\end{tabular}

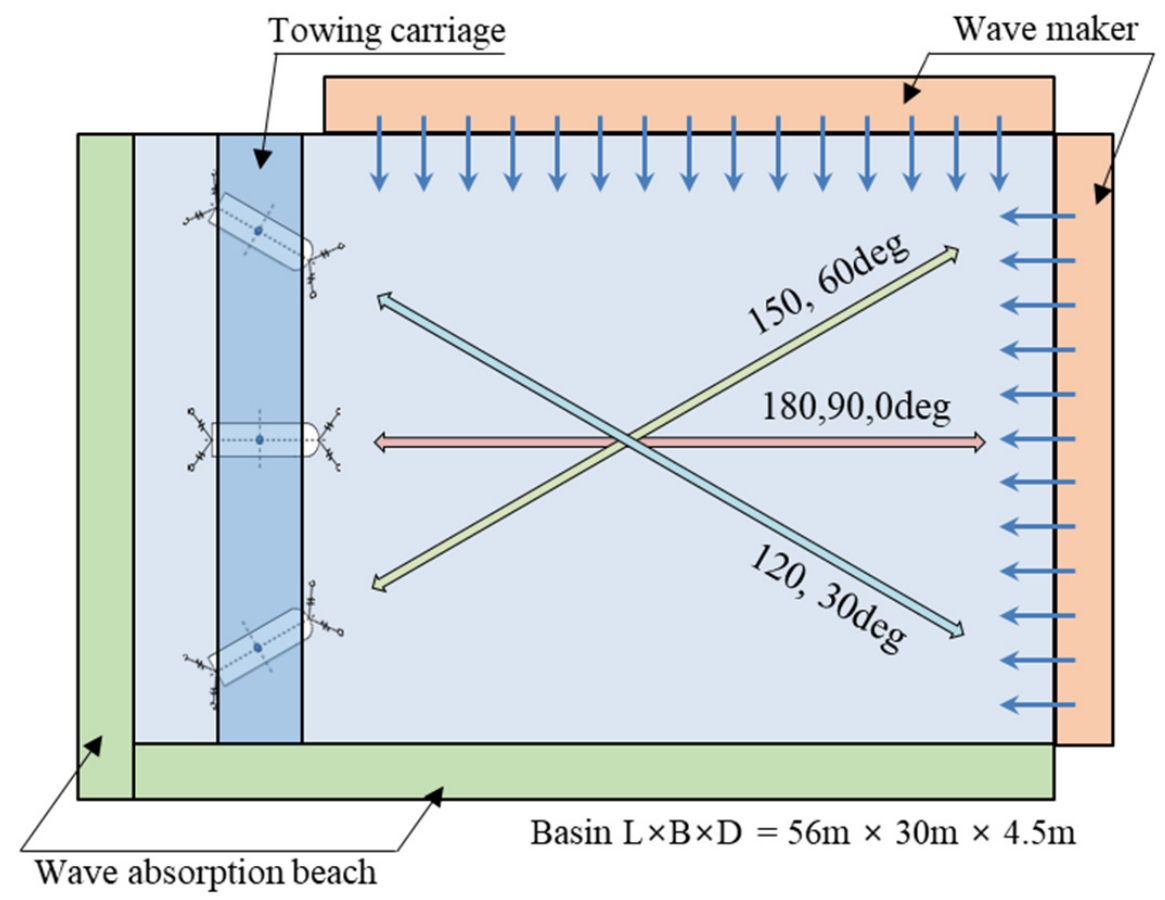

Figure 2. Ocean engineering basin in KRISO.

\subsection{Measurement}

Table 3 presents the measuring items in this model test. The 6-DOF motions of the ship were directly measured by using a non-contact optical measurement system. The relative wave motions were also measured at the fore, mid starboard, and aft locations of the ship using capacitance-type wave probes. Additionally, the wave heights at the fore and aft parts of the ship were measured to check the incident wave. The tensions of the soft spring-type mooring line were measured using tensiometers, and global forces at the fore and aft parts were measured using 2-axis load cells. 
Table 3. Measuring items of model test.

\begin{tabular}{ccc}
\hline Measurement Item & Sensor & \# of Channels \\
\hline 6-DOF motions & RODYM & 6 \\
Wave elevation & Capacitance-type wave probe & 2 \\
Relative wave motion & Capacitance-type wave probe & 3 \\
Mooring line tension & 1-axis load cell & 4 \\
Global force & 2-axis load cell & 4 \\
\hline \multicolumn{2}{c}{ Total channels } & 19 \\
\hline
\end{tabular}

To measure the surge-, sway-, and yaw-directional wave drift force and moment, the model ship was restrained with a soft spring system consisting of four horizontal springs and pulley systems, as shown in Figure 3. Two springs were connected to the ship's bow, whereas the other two springs were connected to the ship's stern. The other ends of the springs were attached to the towing carriage, and the carriage towed the model at a constant speed. The spring's stiffness was chosen such that the natural period of planar motion was more than five times the highest wave period. Tensiometers were installed to measure the line tension at the end of the springs attached to the carriage. Two springs were attached to each point on the bow and stern (GF1, GF2), and 2-axis load cells were installed to measure the global load, as shown in Figure 3. The wave drift force can be estimated using the tensiometers of the four lines (indirect method) or two load cells (direct method). In this study, the wave drift forces evaluated by the two methods were compared. Typically, the overall tendency of the wave drift force derived from the four tensiometers was similar to that from the two load cells. In contrast, the values obtained from the tensiometers were slightly smaller because of friction at the pulleys (Figure $3 \mathrm{~b}$ ) used to connect the springs and tensiometers.

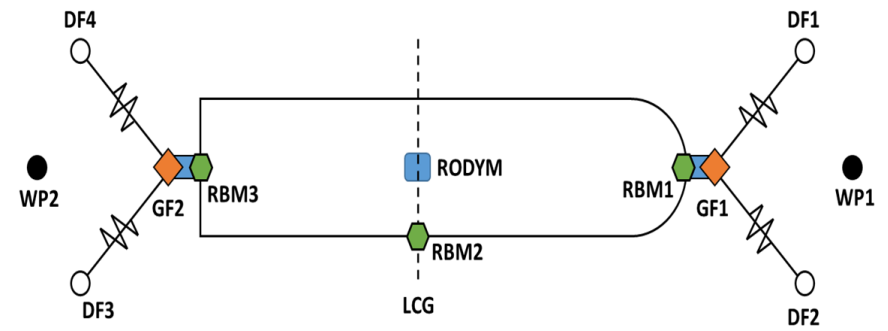

(a) Schematic diagram of the model test
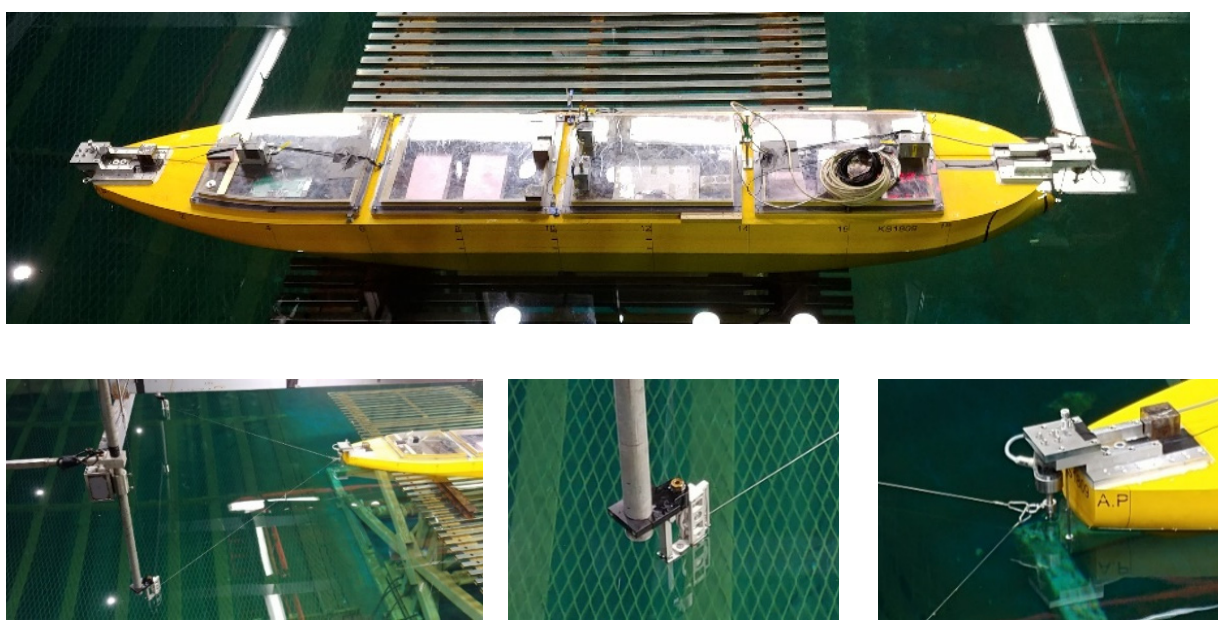

(b) Pictures of the model set-up

Figure 3. Configuration of model test. 


\subsection{Data Analysis}

The ship was constrained to the towing carriage by a soft spring-type mooring system and towed at a constant speed in the model test. A ship moving in the waves exhibits 6-DOF motion, as shown in Figure 4. Typically, a ship should have constant speed during the model test. However, the vessel had constant speed, acceleration, and deceleration regions during the test, as shown in Figure 5a. The constant speed region was defined, as shown in Figure 5a, and it was used to estimate the values of the wave drift forces. Planar motions such as surge, sway, and yaw motions have low-frequency motion as well as wave-frequency motion. The amplitude of the wave frequency motion, which is the motion response amplitude operator (RAO), could be extracted using Fourier transform.
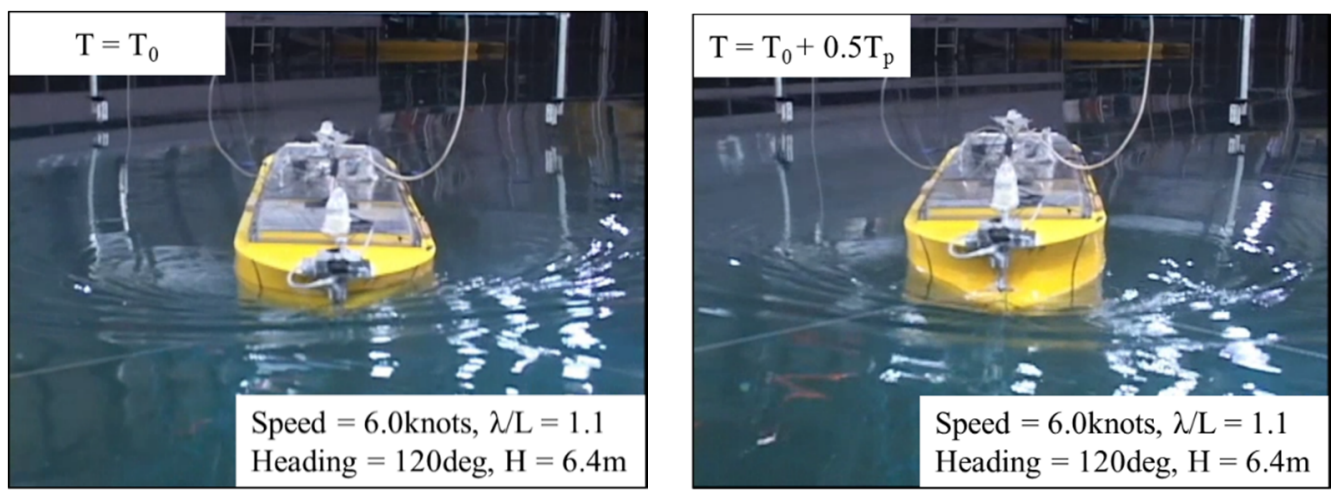

Figure 4. Snapshots of experiment: Speed $=6.0 \mathrm{knots}, \lambda / \mathrm{L}=1.1$, heading $=120 \mathrm{deg}, \mathrm{H}=6.4 \mathrm{~m}$.

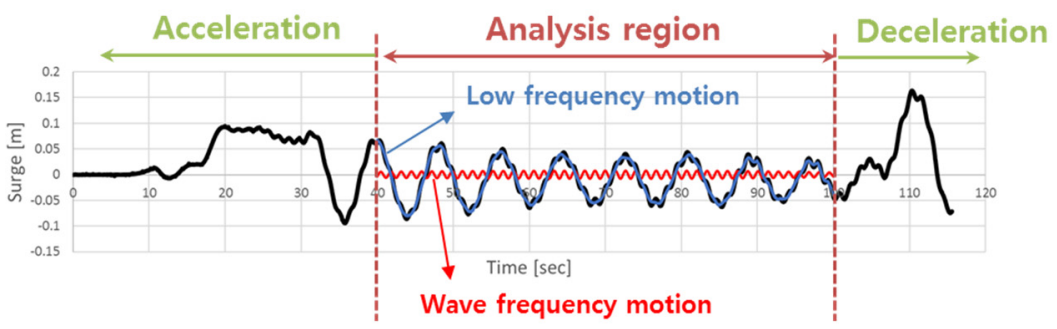

(a) Time histories of surge-directional motion signal

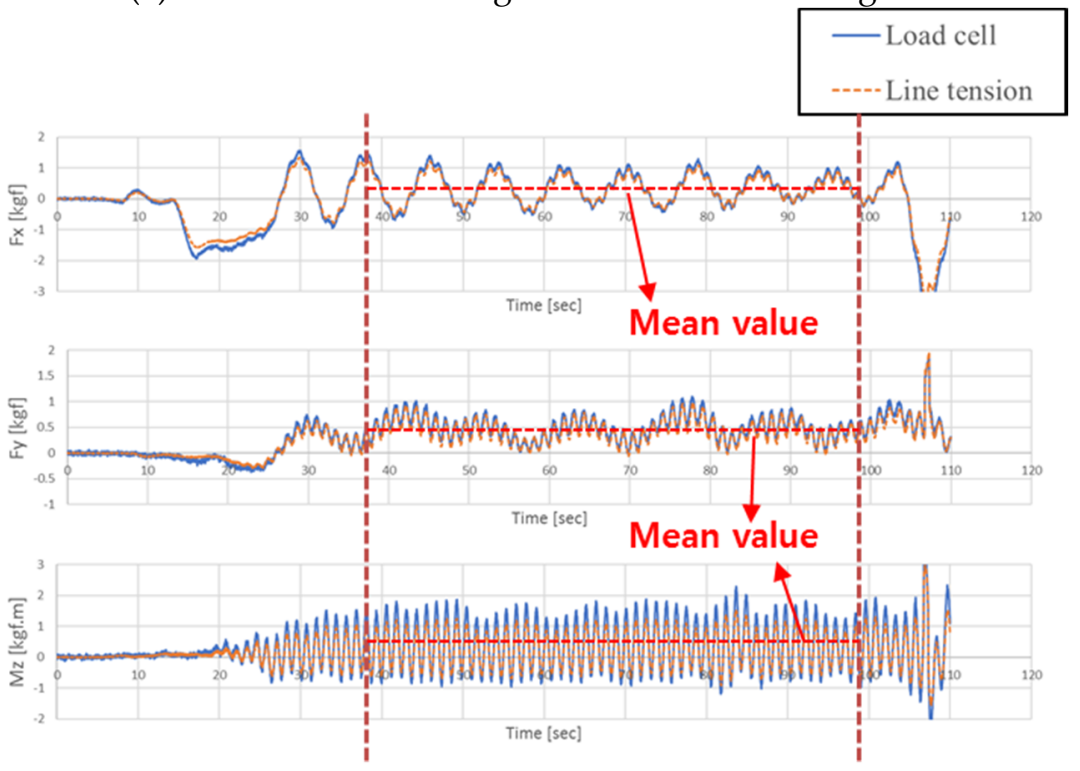

(b) Time histories of surge, sway, and yaw force and moment

Figure 5. Examples of time histories. 
Figure $5 \mathrm{~b}$ shows the examples of time histories of the wave drift force and moment. The mean values of each signal are defined as the wave drift force and moment. There are two types of data in these figures: Time signals from the global load cells (direct method, blue line) and time signals from the tensiometers (indirect method, orange line). It can be seen that the overall tendencies in these two methods are similar to each other, whereas the wave drift force derived from the tension meters are smaller, owing to the friction of the pulley.

\section{Numerical Method}

In this study, the SWAN1 program initially developed by MIT [38] and modified by KRISO was used. It is based on the Rankine panel method in the frequency domain under the assumption of potential flow. The ship fixed coordinate system is defined in Figure 6a to solve the ship motion problem. It is assumed that a ship has forward speed, V, in the presence of incident waves. The incident wave are characterized by the amplitude $\mathrm{A}$, frequency $\omega$, and heading angle $\beta$.
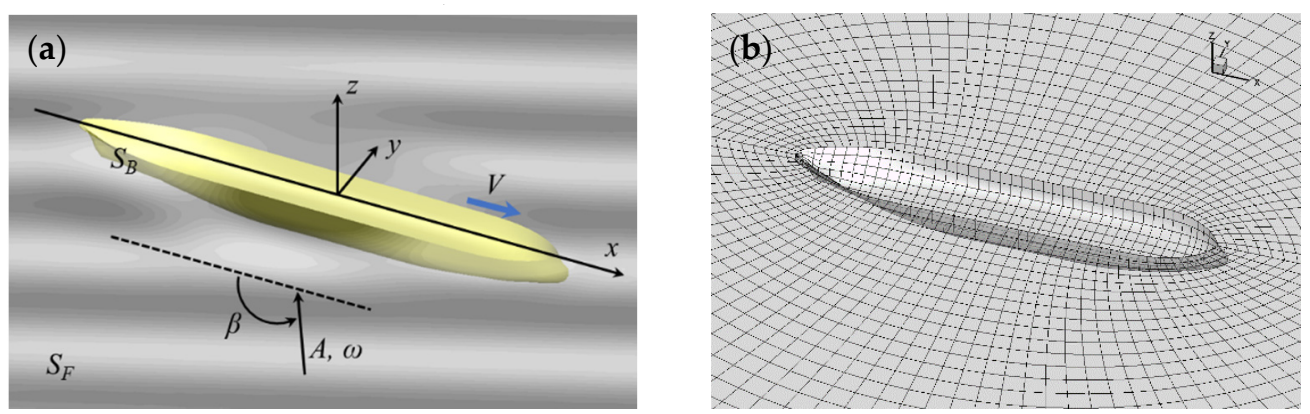

Figure 6. Coordinate system (a) and examples of panel model (b) for numerical method.

To linearize the boundary value problem, the velocity potential is decomposed as follows:

$$
\Psi(\vec{x}, t)=\Phi(\vec{x})+\operatorname{Re}\left(\left[A\left(\varphi_{I}+\varphi_{D}\right)+\sum_{j=1}^{6} \xi_{j} \varphi_{j}\right] e^{i \omega t}\right)
$$

where $\Phi$ denotes the steady potential, which does not change with time. $\varphi_{I}, \varphi_{D}$, and $\varphi_{j}$ denote the incident wave potential, diffraction wave potential for the unit wave height, and radiation wave potential for the unit motion, respectively. The linearized boundary value problem for the radiation potential and diffraction potential can be written as follows:

$$
\nabla^{2} \varphi_{j}=0 \quad \text { in fluid domain, }
$$

$g \frac{\partial \varphi_{j}}{\partial z}=\omega^{2} \varphi_{j}-2 i \omega \nabla \Phi \cdot \nabla \varphi_{j}-\nabla \Phi \cdot \nabla\left(\nabla \Phi \cdot \nabla \varphi_{j}\right)-\frac{1}{2} \nabla(\nabla \Phi \cdot \nabla \Phi) \cdot \nabla \varphi_{j}+\Phi_{z z}\left(i \omega \varphi_{j}+\nabla \Phi \cdot \nabla \varphi_{j}\right) \quad$ on $\mathrm{z}=0$

$$
\begin{gathered}
\frac{\partial \varphi_{j}}{\partial n}=i \omega n_{j}+m_{j} \quad \text { on } \bar{S}_{B} \\
\nabla^{2} \varphi_{D}=0 \quad \text { in fluid domain } \\
g \frac{\partial \varphi_{D}}{\partial z}=-g \frac{\partial \varphi_{I}}{\partial z}+\omega^{2}\left(\varphi_{I}+\varphi_{D}\right)-2 i \omega \nabla \Phi \cdot \nabla\left(\varphi_{I}+\varphi_{D}\right)-\nabla \Phi \cdot \nabla\left(\nabla \Phi \cdot \nabla\left(\varphi_{I}+\varphi_{D}\right)\right) \\
-\frac{1}{2} \nabla(\nabla \Phi \cdot \nabla \Phi) \cdot \nabla\left(\varphi_{I}+\varphi_{D}\right)+\Phi_{z z}\left(i \omega\left(\varphi_{I}+\varphi_{D}\right)+\nabla \Phi \cdot \nabla\left(\varphi_{I}+\varphi_{D}\right)\right) \quad \text { on } z=0 \\
\frac{\partial \varphi_{D}}{\partial n}=-\frac{\partial \varphi_{I}}{\partial n} \quad \text { on } \bar{S}_{B}
\end{gathered}
$$

where $S_{B}$ and $S_{F}$ denote the body surface and free surface, respectively. $m_{j}$ denotes the $\mathrm{m}$-term which includes interaction between the steady and unsteady solutions [38]. 
The equation of motion in the frequency domain can be written as follows:

$$
\begin{aligned}
& \sum_{j=1}^{6}\left[-\omega^{2}\left(m_{i j}+a_{i j}\right)+i \omega b_{i j}+c_{i j}\right] \xi_{j}=X_{i} \quad(i=1, \cdots, 6) \\
& a_{i j}=-\frac{\rho}{\omega^{2}} \operatorname{Re}\left\{\iint_{\bar{S}_{B}}\left(i \omega \varphi_{j}+\nabla \Phi \cdot \nabla \varphi_{j}\right) n_{i} d s\right\} \\
& b_{i j}=\frac{\rho}{\omega^{2}} \operatorname{Im}\left\{\iint_{\bar{S}_{B}}\left(i \omega \varphi_{j}+\nabla \Phi \cdot \nabla \varphi_{j}\right) n_{i} d s\right\} \\
& X_{i}=-\rho \operatorname{Re}\left\{\iint_{\bar{S}_{B}}\left(i \omega\left(\varphi_{I}+\varphi_{D}\right)+\nabla \Phi \cdot \nabla\left(\varphi_{I}+\varphi_{D}\right)\right) n_{i} d s\right\}
\end{aligned}
$$

where $a_{i j}, b_{i j}$ are the added mass and damping matrix, which are functions of the encounter frequency, and $m_{i j}, c_{i j}$ denote the mass and restoring matrix, respectively. $X_{i}$ is the wave excitation force vector. The added mass, damping force, and excitation force can be written as functions of the velocity potentials of the incident, diffraction, and radiation waves. The details of this numerical background can be found in literature [38].

Figure 7 shows the computed total (upper) and scattered (lower) wave contours near KVLCC2 at the forward speed of 6 knots. The wave directions in the left, middle, and right figures are head sea $\left(\beta=180^{\circ}\right)$, bow quartering sea $\left(\beta=120^{\circ}\right)$, and stern quartering sea $\left(\beta=30^{\circ}\right)$, respectively. As shown in these figures, the Kelvin wave is not apparent because KVLCC2 is a low-speed full ship, and the height and shape of the scattered wave vary with the wave direction.

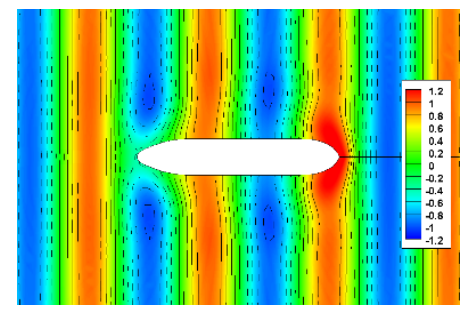

(a) Total wave $\left(\beta=180^{\circ}\right)$

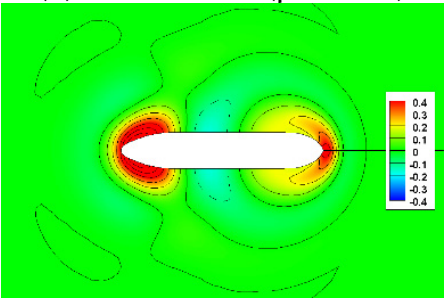

(d) Scattered wave $\left(\beta=180^{\circ}\right)$

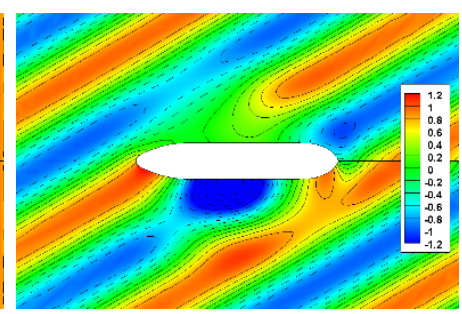

(b) Total wave $\left(\beta=120^{\circ}\right)$

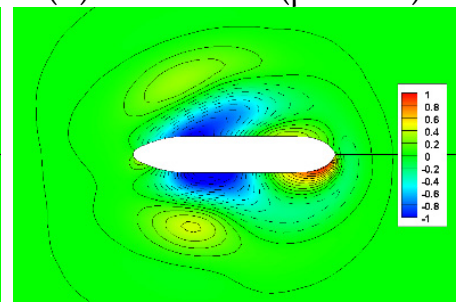

(e) Scattered wave $\left(\beta=120^{\circ}\right)$

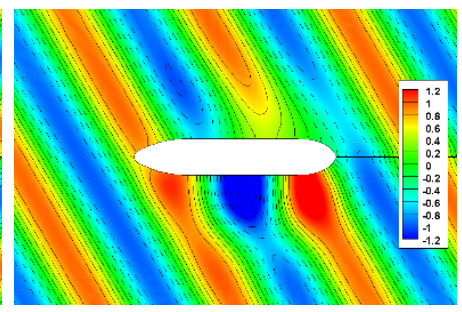

(c) Total wave $\left(\beta=30^{\circ}\right)$

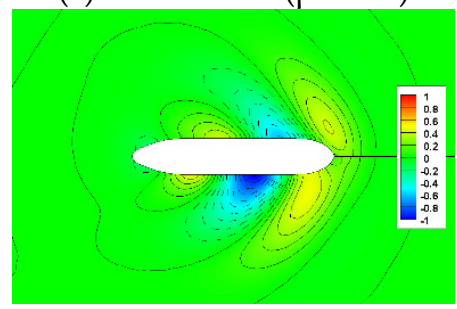

(f) Scattered wave $\left(\beta=30^{\circ}\right)$

Figure 7. Wave contours near the KVLCC2: $\mathrm{V}=6$ knots, $\lambda / \mathrm{L}=0.6$.

The direct pressure integration method is used to calculate the wave drift force on a ship. It is computed by integrating the second-order pressure on the body surface. The wave drift force can be formulated as follows:

$$
\begin{aligned}
\vec{F}_{W D F}= & \frac{1}{2} \rho g \int_{W L}\left[\zeta_{I}+\zeta_{d}-\left(\xi_{3}+\xi_{4} Y-\xi_{5} X\right)\right]^{2} \frac{\vec{N}}{\sin \alpha} d l \\
& -\rho \iint_{\bar{S}_{B}}\left[\frac{1}{2} \nabla\left(\phi_{I}+\phi_{d}\right) \cdot \nabla\left(\phi_{I}+\phi_{d}\right)\right] \vec{N} d S \\
& -\rho \iint_{\bar{S}_{B}}\left[\vec{\xi} \vec{\zeta}_{S} \cdot \nabla\left(i \omega\left(\phi_{I}+\phi_{d}\right)\right)+H X \vec{X} \cdot \nabla g Z\right] \vec{N} d S \\
& -\rho \iint_{\bar{S}_{B}}\left[i \omega\left(\phi_{I}+\phi_{d}\right)-(\vec{U}-\nabla \Phi) \cdot \nabla\left(\phi_{I}+\phi_{d}\right)+g\left(\xi_{3}+\xi_{4} Y-\xi_{5} X\right)\right] \vec{N}_{1} d S \\
& -\rho \iint_{\bar{S}_{B}}[g Z] \vec{N}_{2} d S
\end{aligned}
$$


It should be noted that a linear solution is used for the wave drift force calculation because the mean value of the second-order solution becomes zero. The details of this formula are available in the literature [39]. The components of the wave drift force can be classified as follows:

$$
\begin{aligned}
\text { Comp. I } & =\frac{1}{2} \rho g \int_{W L}\left[\zeta_{I}+\zeta_{d}-\left(\xi_{3}+\xi_{4} Y-\xi_{5} X\right)\right]^{2} \frac{\vec{N}}{\sin \alpha} d l \\
\text { Comp. II } & =-\rho \iint_{\bar{S}_{B}}\left[\frac{1}{2} \nabla\left(\phi_{I}+\phi_{d}\right) \cdot \nabla\left(\phi_{I}+\phi_{d}\right)\right] \vec{N} d S \\
\text { Comp. III } & \left.=-\rho \iint_{\bar{S}_{B}} \vec{\xi}_{S} \cdot \nabla\left(i \omega\left(\phi_{I}+\phi_{d}\right)\right)+H X \vec{X} \cdot \nabla g Z\right] \vec{N} d S \\
\text { Comp. IV } & =-\rho \iint_{\bar{S}_{B}}\left[i \omega\left(\phi_{I}+\phi_{d}\right)-(\vec{U}-\nabla \Phi) \cdot \nabla\left(\phi_{I}+\phi_{d}\right)+g\left(\xi_{3}+\xi_{4} Y-\xi_{5} X\right)\right] \vec{N}_{1} d S-\rho \iint_{\bar{S}_{B}}[g Z] \vec{N}_{2} d S
\end{aligned}
$$

Components I, II, III, and IV denote the component of waterline integration, the squared component of first-order velocity, the component representing the product of ship motion and pressure, and the components related to the ship's rotational motion, respectively. Figure 8 shows the components of the wave drift force and moment on KVLCC 2 at the bow quartering sea $\left(\beta=120^{\circ}\right)$. As shown in these figures, there were significant values near the region corresponding to $\lambda / L<1.0$ and roll resonance frequency $(\lambda / L=1.6)$. It can be seen that large roll motion could affect the wave drift force component, especially components I, III, and IV. As mentioned before, the Rankine panel method was adopted in this study; thus, the panel should be distributed on the free surface as well as the body surface, as shown in Figure 6b. The O-type free surface grid was used, and the diameter of the free surface was approximately four times the incident wavelength. A numerical wave damping zone was applied to satisfy the radiation condition. The numerical wave damping zone was distributed around the truncated boundary of the free surface.

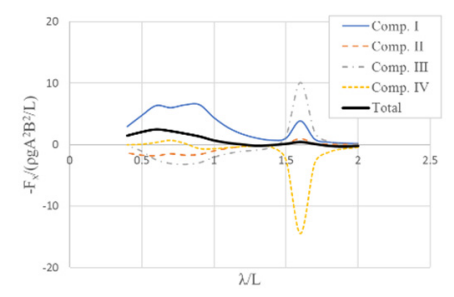

(a) Fx components

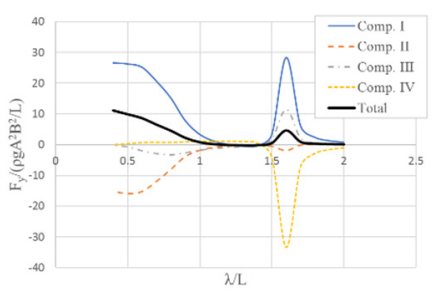

(b) Fy components

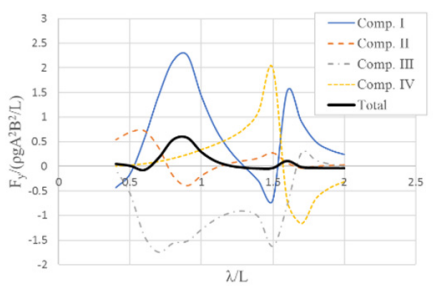

(c) Mz components

Figure 8. Components of wave drift force on KVLCC2: $V=6$ knots, $H / L=1 / 50, \beta=120^{\circ}$.

\section{Results}

\subsection{Motion RAOs}

In principle, the wave drift forces acting on a ship are dominantly affected by the ship's motion responses as well as the surrounding wave fields; therefore, the motion responses of the ship must be predicted with high accuracy. In this section, the motion RAOs of KVLCC2 are first checked. Figure 9 shows the surge, heave, and pitch motion RAOs of KVLCC2 under head sea conditions $\left(\beta=180^{\circ}\right)$. In the figures, the results of two different forward speeds are presented together for comparison. The rectangular and circular symbols denote the experimental data for 6.0 and 15.5 knots, respectively. The two lines indicate the calculation results based on the linear potential analysis. The $x$-axis represents the wavelength divided by the ship length, whereas the $y$-axis represents the motion RAOs normalized by the wave amplitude. Under the long wave condition with a wavelength ratio of 1.0 or more, it can be observed that the heave and pitch motions increased significantly due to the forward speed effect. However, they showed a slight decrease under the shortwave conditions, where the wavelength was less than the ship length. In the case of surge motion, the overall response was lower at high-speed conditions. As the ship's forward speed increased in a head sea, the encounter frequency became higher than the wave frequency, and the scattered wave fields around the ship changed simultaneously. 
Consequently, the motion characteristics of the ship altered according to the ship speed for the same wavelength. Comparing the model test data with the numerical calculations showed good agreement in the overall tendencies and magnitudes. Nevertheless, a few points (for example, 15.5 knots, pitch $\mathrm{RAO}, \lambda / \mathrm{L}=1.5$ ) did not agree well. In the numerical calculation, the steady potential was calculated using the double-body approximation. The double-body approximation was appropriate for the blunt and low-speed vessel. Therefore, motion RAOs showed a little discrepancy at the high-speed case (15.5 knots).

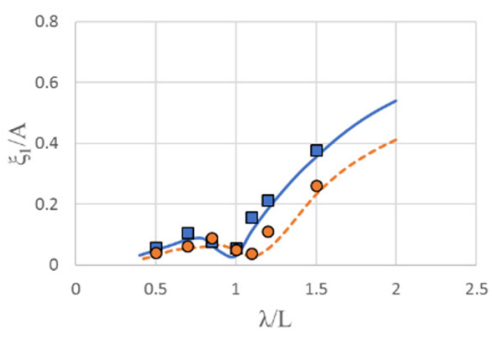

(a) Surge motion RAOs

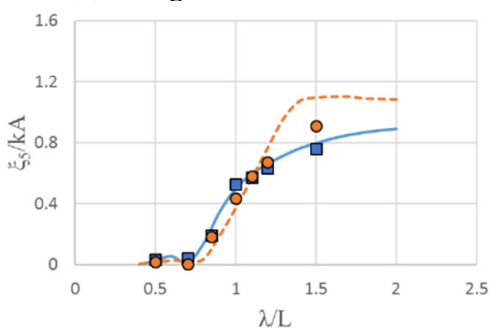

(c) Pitch motion RAOs

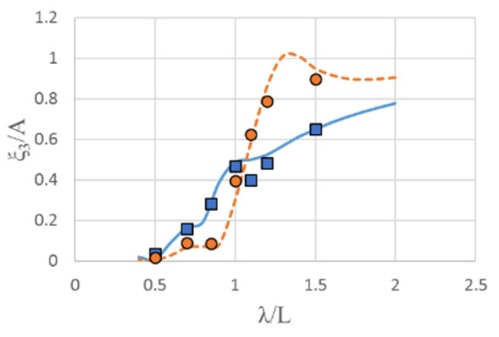

(b) Heave motion RAOs

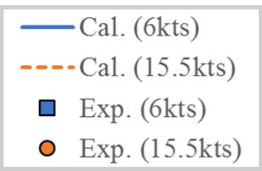

Figure 9. Motion response amplitude operators (RAOs) of KVLCC2: $\beta=180^{\circ}, \mathrm{H} / \mathrm{L}=1 / 50$.

Figure 10 compares the motion RAOs of bow quartering sea $\left(\beta=120^{\circ}\right)$ and stern quartering sea $\left(\beta=60^{\circ}\right)$, where the ship experiences all 6 degrees-of-freedom motions. In the figures, symbols and lines denote the experimental data and computation results, respectively. Blue and orange colors indicate bow quartering sea and stern quartering sea, respectively. It can be observed that the overall motion characteristics of the ship vary greatly with the wave direction. The surge motion RAOs increased significantly in the stern quartering sea when compared with the bow quartering sea. It can also be observed that the heave motion of bow quartering sea was larger than that of stern quartering sea, whereas the opposite tendency was observed for pitch motion. The roll motion RAOs clearly showed the roll resonance point shift due to the encounter frequency effect. In the bow quartering sea, the encounter frequency became higher than in the original wave frequency, which caused the ship motion resonances to move to the long wavelength range. On the contrary, the motion resonances were shifted to the short wavelength range in the stern quartering sea. In numerical computations, the effect of viscous roll damping should be considered to calculate the accurate resonant roll response. In this study, linearized viscous roll damping was considered approximately $2 \%$ of the critical roll damping obtained from the free roll-decay test. As shown in these figures, the overall tendencies of the experimental data were very similar to those of the computational results. Through this comparison, it can be concluded that the numerical analysis used in the study can predict the 6 DOF motion of the ship with high accuracy. 


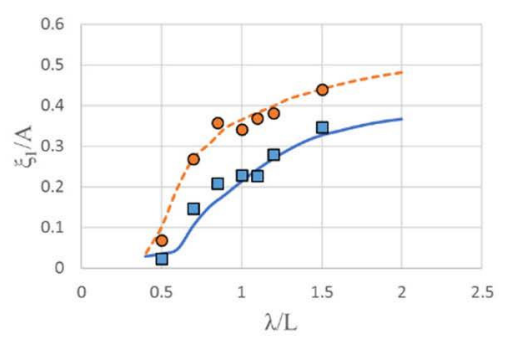

(a) Surge motion RAOs

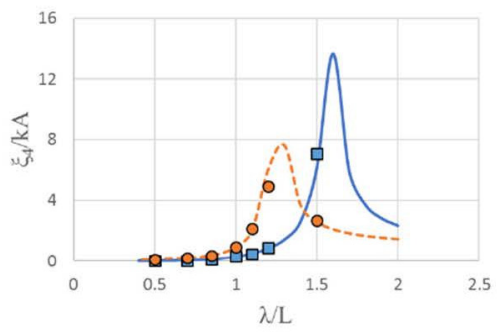

(d) Roll motion RAOs

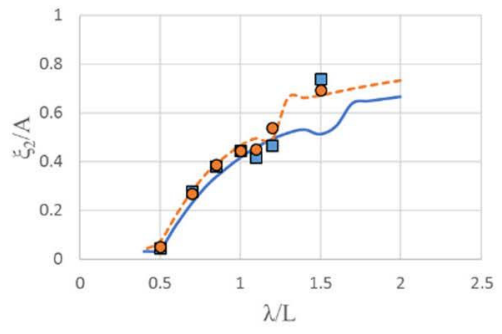

(b) Sway motion RAOs

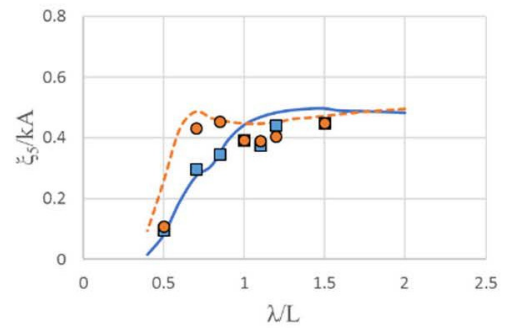

(e) Pitch motion RAOs

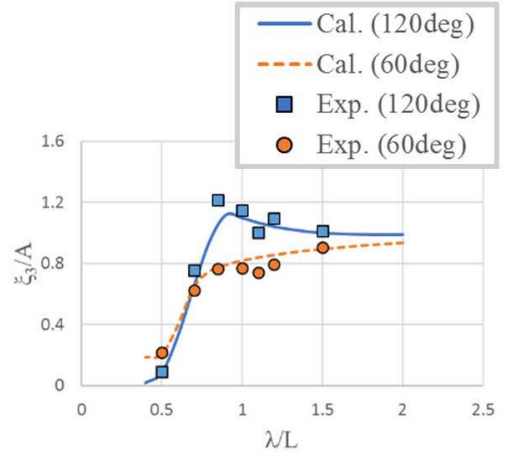

(c) Heave motion RAOs

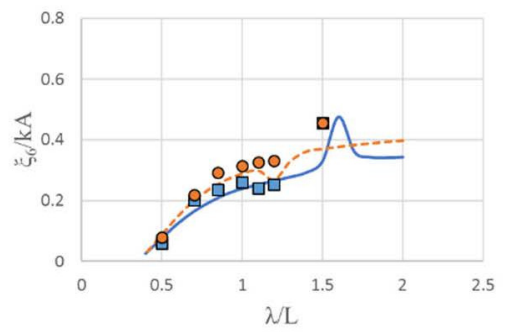

(f) Yaw motion RAOs

Figure 10. Motion RAOs of KVLCC2: $V=6$ knots, $\mathrm{H} / \mathrm{L}=1 / 50$.

\subsection{Surge Wave Drift Force (Added Resistance)}

In this section, the surge wave drift force data are presented and discussed by comparing with numerical results. Figure 11 shows the surge wave drift force results when KVLCC2 was moving forward at a speed of 6 knots. Here, 7 wave directions were considered ranging from head sea $\left(\beta=180^{\circ}\right)$ to following sea $\left(\beta=0^{\circ}\right)$ at $30^{\circ}$ intervals. Each figure had three results: The gray square denotes the result measured from the experiment using the force sensor, the orange diamond denotes the experimental results obtained from the tensiometer, and the solid blue line denotes the numerical result of the present computations. The $x$ - and $y$-axes show the values of the non-dimensional wavelengths and wave drift forces, respectively. Firstly, under the head sea condition, it can be seen that the surge drift force became the largest at the wavelength ratio around 0.85 and converged to a constant value as the wavelength reduced. The maximum surge drift forces were found in the bow quartering sea $\left(150\right.$ and $\left.120^{\circ}\right)$ at a wavelength ratio of around 0.7 . However, it can be observed that the surge drift forces tended to significantly decrease when encountering stern waves. The data from the tensiometers were slightly smaller than those from the force sensors. The friction loss due to the pulley system may have reduced the data measured by the tensiometer. Therefore, the results from the force sensor were considered more reliable.

A comparison of the present numerical results with the experimental data at head sea $\left(\beta=180^{\circ}\right)$ and bow quartering sea $\left(\beta=150,120^{\circ}\right)$ showed that the overall tendencies were similar to each other. However, the present numerical results underestimated the surge drift forces, especially in the short wavelength region of less than $\lambda / L=0.8$. This was because under the short-wave conditions of the head and bow quartering sea, the ship motion was negligible and the nonlinear amplification effect became significant owing to fully reflected waves from the ship bow section. Because of these discrepancies in the short wavelength region, various correction formulas have been proposed to complement the differences in the surge wave drift forces obtained from the numerical computations. For example, Fujii and Takahashi [29] and Faltinsen et al. [11] proposed a semi-empirical formula and an asymptotic formula, respectively. Recently, the National Maritime Research Institute (NMRI) in Japan ([22,23]) suggested a complementary approach to the method proposed 
by Fujii and Takahashi. In this study, the NMRI method was applied to complement the present numerical results of the surge wave drift force under a short wavelength. The NMRI's method can be expressed as follows:

$$
\begin{aligned}
& \alpha_{d} \cdot F_{\text {short }}=\alpha_{d}\left(1+\alpha_{U}\right)\left[\frac{1}{2} \rho g \zeta_{I}^{2} B B_{f}(\beta)\right] \\
& \quad B_{f}(\beta)=\frac{1}{B}\left[\int_{I} \sin ^{2}(\theta-\beta) \sin \theta d l+\int_{I I} \sin ^{2}(\theta+\beta) \sin \theta d l\right] \\
& \quad \alpha_{d}=\frac{\pi^{2} I_{1}^{2}\left(k_{e} d\right)}{\pi^{2} I_{1}^{2}\left(k_{e} d\right)+K_{1}^{2}\left(k_{e} d\right)}, \quad\left(k_{e}=\frac{\omega_{e}^{2}}{g}\right) \\
& 1+\alpha_{u}=1+C_{U} F_{n}
\end{aligned}
$$

where $B_{f}, \alpha_{d}$, and $1+\alpha_{U}$ denote the bluntness coefficient, reflection coefficient, and advance coefficient, respectively. In this formula, $C_{U}$ can be calculated using the empirical formula derived from various types of ships; however, because the added resistance under short wavelengths acting on KVLCC 2 was measured by the model test, the $C_{U}$ value was derived using these experimental data. The details of this formula have been summarized in the reports by Kuroda et al. [22] and Tsujimoto et al. [23]. The following equation was applied to compensate the surge wave drift force under short wavelengths using these values.

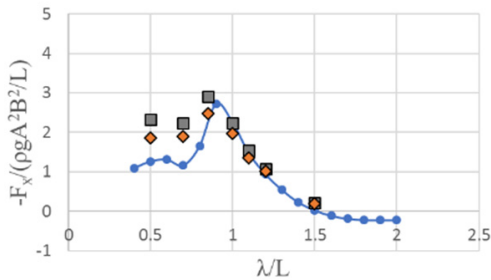

(a) $\beta=180^{\circ}$

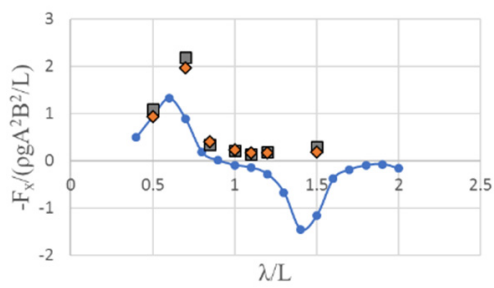

(d) $\beta=90^{\circ}$

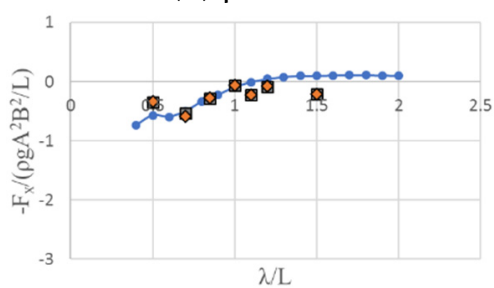

(g) $\beta=0^{\circ}$

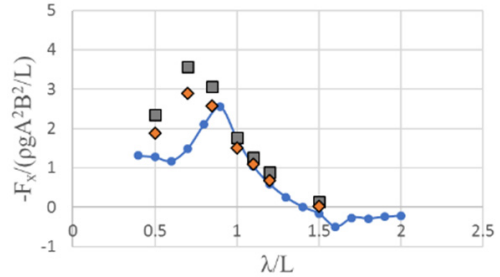

(b) $\beta=150^{\circ}$

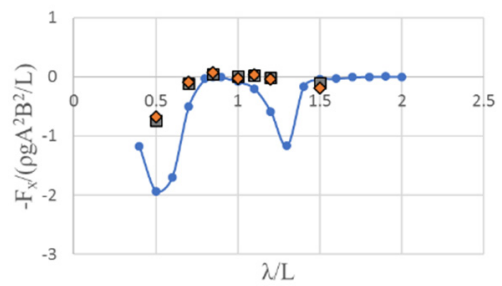

(e) $\beta=60^{\circ}$

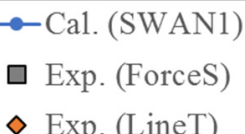

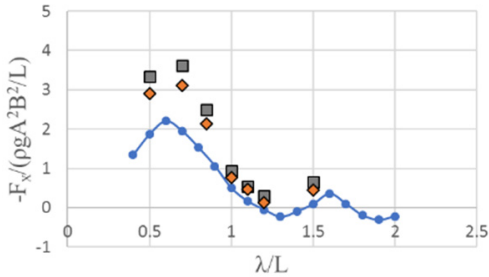

(c) $\beta=120^{\circ}$

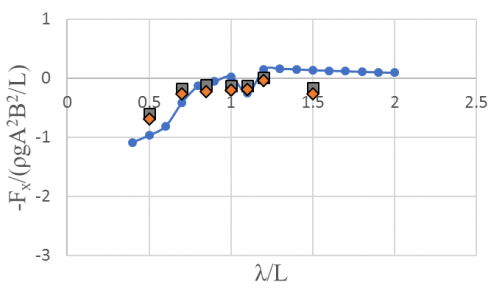

(f) $\beta=30^{\circ}$

Figure 11. Surge drift force on KVLCC2: $V=6$ knots, $H / L=1 / 50$.

$$
F_{x, \text { modi }}=F_{\text {SWAN1 }}+\alpha_{d} \cdot F_{\text {short }}
$$

The above equation suggests that the potential-based computation results were corrected by simply adding the values of the short-wave-induced drift force using the NMRI method. Figure 12 compares the original and corrected results of the surge drift force by applying this method. The figures on the left and right show the results of the head sea $\left(\beta=180^{\circ}\right)$ and bow quartering sea $\left(\beta=120^{\circ}\right)$, respectively. As shown in this figure, the results with the NMRI correction showed better agreement with the experimental data than the original results.

Polar diagrams are presented in Figure 13 to reveal the overall characteristics of the surge drift force more clearly. In these figures, the radial ( $r$ ) direction denotes the wave- 
length ratio, and the circumferential $(\theta)$ direction denotes the wave direction. The contour level shows the magnitude of the surge drift force. Figure 13a depicts the experimental results, and Figure 13b,c depicts the original computation results and modified computation results, respectively. As shown in these figures, large surge drift forces were observed near the bow quartering sea $\left(\theta=180,150,120^{\circ}\right)$ at the wavelength ratio of approximately 0.7 . Under the short wavelength region of the head sea, it can be observed that the modified computation results were closer to the experimental data than the original ones. The surge drift force tended to decrease from 120 to $0^{\circ}$ gradually, and negative values could be observed near the stern quartering sea region $\left(\theta=30,0^{\circ}\right)$. It can be seen that the overall tendencies were very similar between the experiments and modified computations. It should be noted that small negative values were found near the stern quartering sea region in the experimental data as well as the computational results. This implied that the ship's total resistance could be decreased when the wave direction was the stern quartering sea.

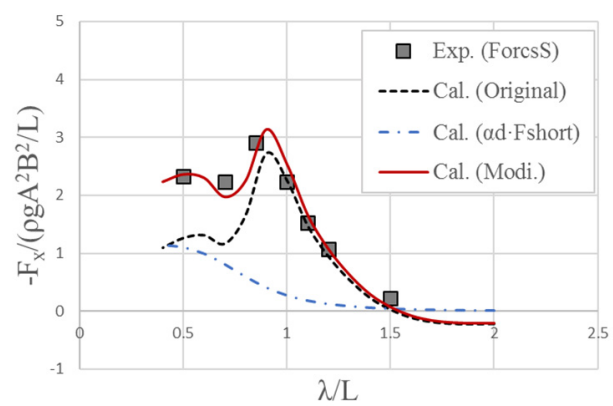

(a) $\beta=180 \mathrm{deg}$

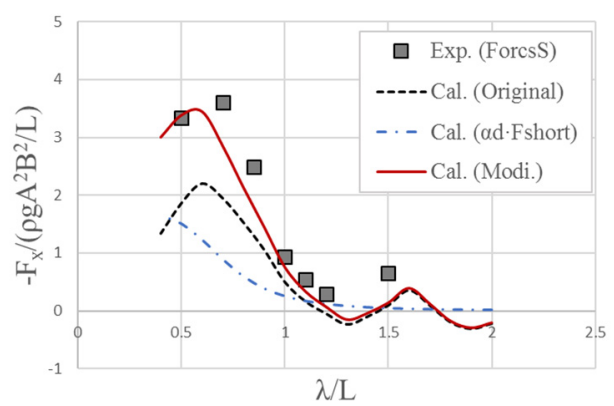

(b) $\beta=120 \mathrm{deg}$

Figure 12. Modification of surge drift force on KVLCC2: $V=6$ knots, $H / L=1 / 50$.

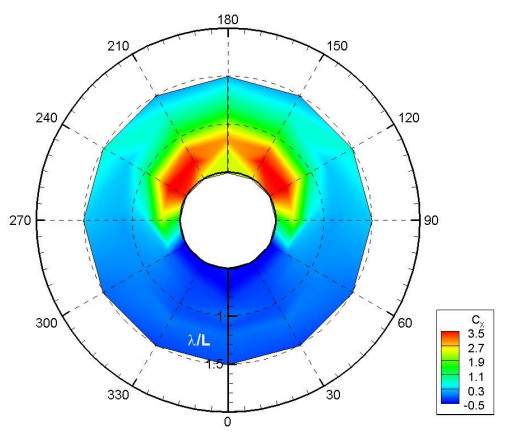

(a) Experiment

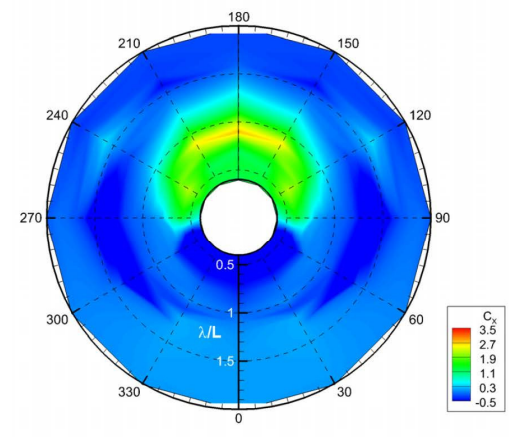

(b) Computation (Original)

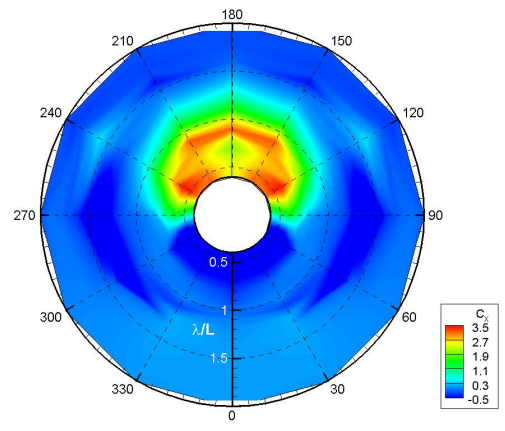

(c) Computation (Modification)

Figure 13. Polar diagram of surge wave drift force: KVLCC2, V = 6 knots. 


\subsection{Sway Wave Drift Force}

In this section, the sway drift force data from the model tests are presented directly compared to the computational results. Figure 14 shows the results of the sway wave drift forces acting on KVLCC2 when advancing at 6 knots. Among the seven wave headings, the sway drift forces were the maximum in the short wavelength region (less than $\lambda / L=1.0$ ) under the beam sea condition. Similar to the surge drift force, the measurements from the tensiometers were slightly lower than those from the force sensors owing to friction loss in the pulley system. Overall, the numerical computations showed reasonable agreement with the experimental data. A small difference between the experimental data and computation results was observed near the roll resonance frequency. This was because the roll motion's resonance may have amplified the wave drift force component related to motion. Figure 15 showed the polar diagram of the sway wave drift force concerning various headings and wavelengths. Figure $15 \mathrm{a}, \mathrm{b}$ represents the experimental data and computation results, respectively. It can be seen from the figure that the two diagrams are very similar except near the roll motion resonance frequency.

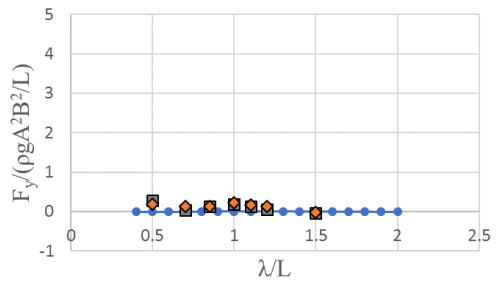

(a) $\beta=180^{\circ}$

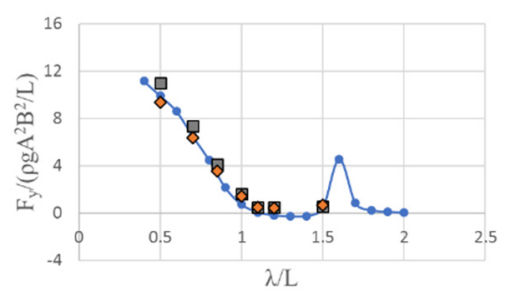

(c) $\beta=120^{\circ}$

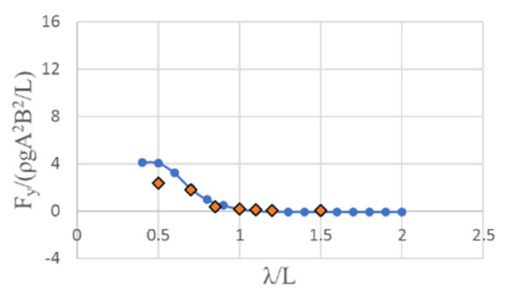

(f) $\beta=30^{\circ}$

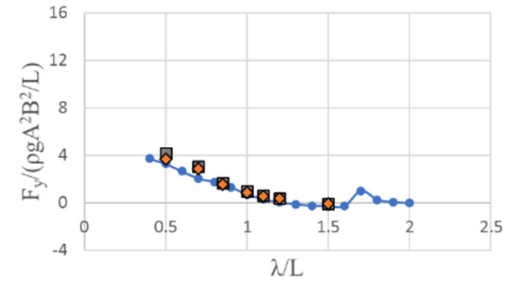

(b) $\beta=150^{\circ}$

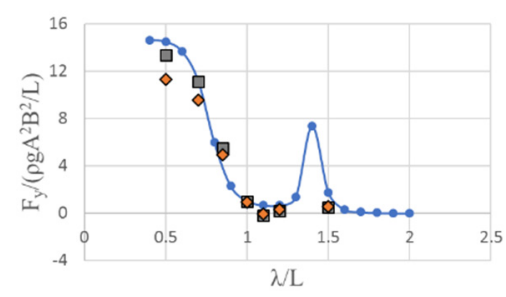

(d) $\beta=90^{\circ}$

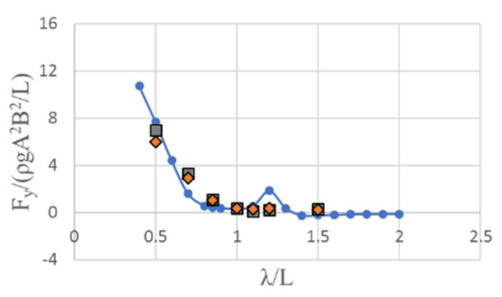

(e) $\beta=60^{\circ}$

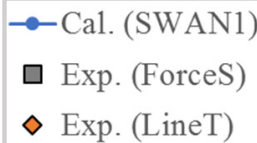

$\diamond$ Exp. (LineT)

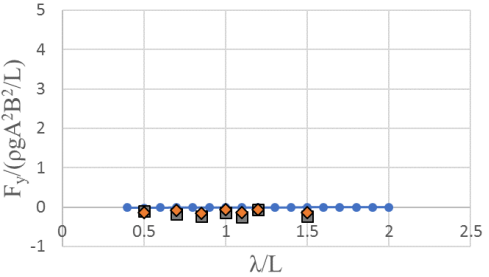

(g) $\beta=0^{\circ}$

Figure 14. Sway drift force on KVLCC2: $V=6$ knots, $H / L=1 / 50$.

\subsection{Yaw Wave Drift Moment}

The yaw wave drift moment on KVLCC2 moving at 6 knots is compared in Figure 16. The following three results are included in each figure: Experimental data from the force sensor and tensiometer, and the numerical computation results. As shown in this figure, the overall trends were similar, but there were significant discrepancies in the yaw drift moment at the bow quartering and stern quartering sea. To show these discrepancies more clearly, the polar diagrams of the yaw drift moment are compared in Figure 17. The differences were mainly found in the bow and stern quartering sea. In the bow quartering sea, the calculated moments were smaller than the experimental data. This was because significant viscous effects due to flow separation occurred in the bow and stern areas, 
changing the longitudinal distribution of the hydrodynamic pressure. This meant that the total summations of the second-order normal pressure on the body surface were similar, but its spatial distribution could be different.

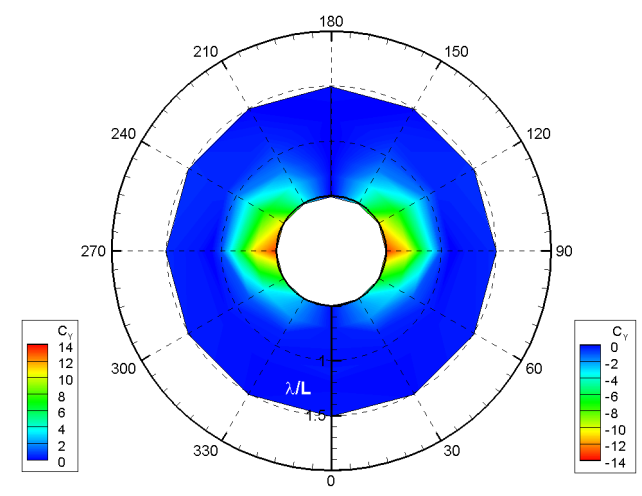

(a) Experiment

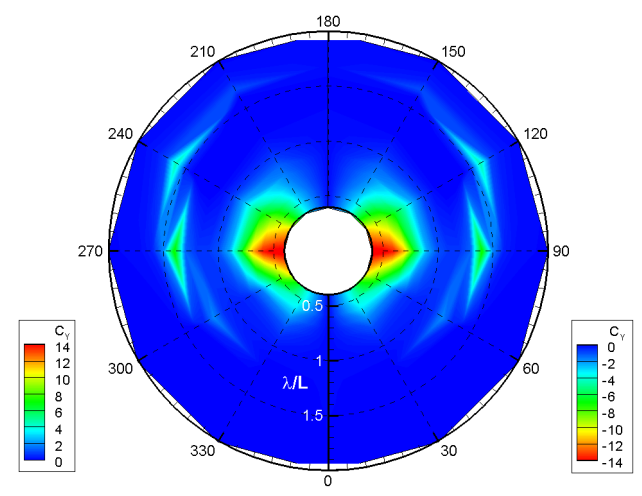

(b) Computation

Figure 15. Polar diagram of sway wave drift force: KVLCC2, V = 6 knots.

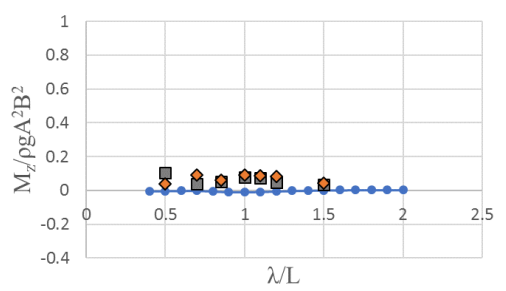

(a) $\beta=180^{\circ}$

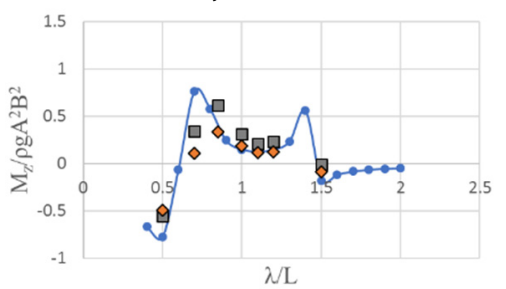

(d) $\beta=90^{\circ}$

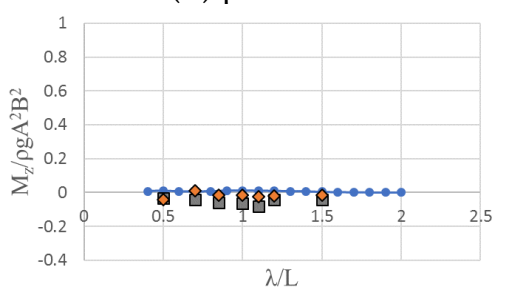

(g) $\beta=0^{\circ}$

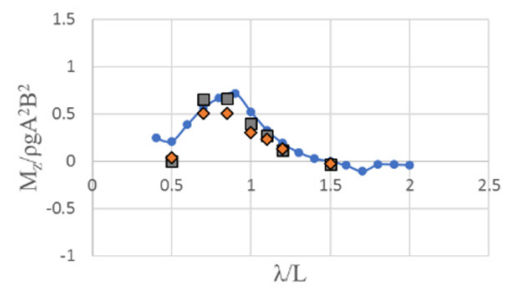

(b) $\beta=150^{\circ}$

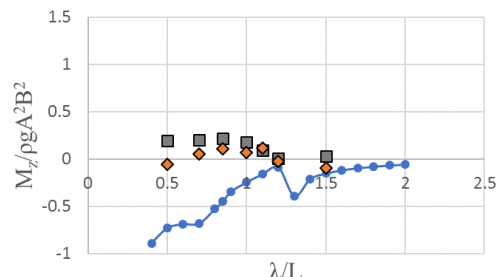

(e) $\beta=60^{\circ}$

-Ca1. (SWAN1)
$\square$ Exp. (ForceS)
$\diamond$ Exp. (LineT)

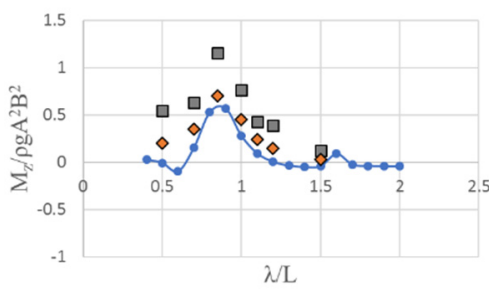

(c) $\beta=120^{\circ}$

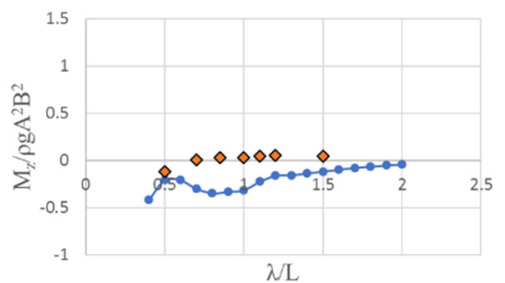

(f) $\beta=30^{\circ}$

Figure 16. Yaw drift moment on KVLCC2: $V=6$ knots, $H / L=1 / 50$.

In order to check these differences, a CFD (Computational Fluid Dynamic) calculation was performed at $\beta=60^{\circ}, \lambda / \mathrm{L}=0.85$ using a popular commercial program STAR-CCM+ (v11.06). The wave elevations around the ship and pressure on the body surface were compared in Figure 18. The left side represents the results of STAR-CCM+, and the right side shows the results of the potential-based program. As shown in the figure, the wave elevations near the bow and the pressure magnitude at the stern were very different from each other. It can be seen that these inconsistencies may have caused a difference in the magnitude of the wave drift moment. 


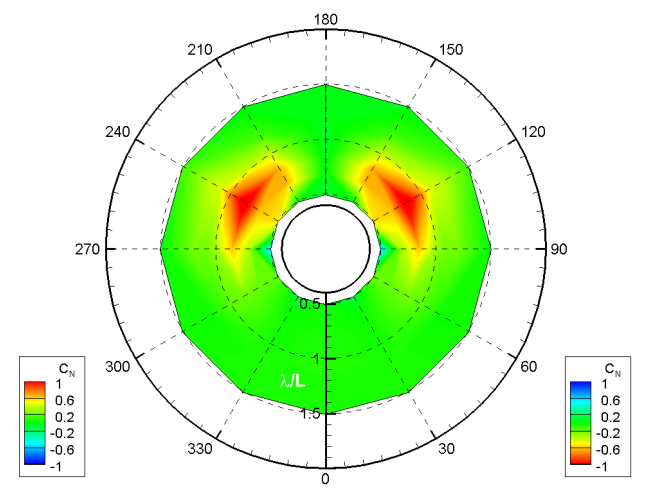

(a) Experiment

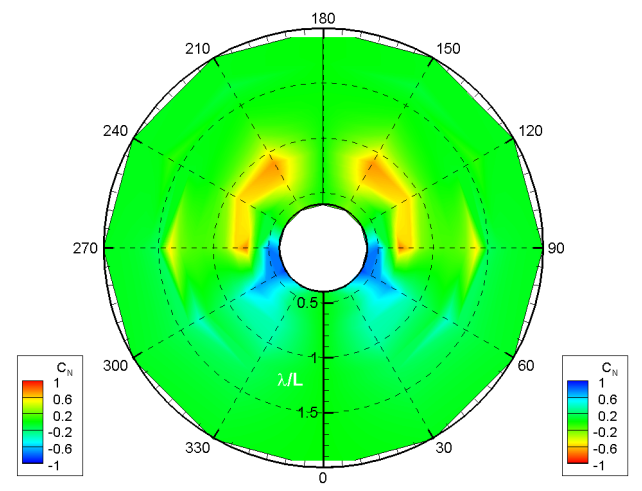

(b) Computation

Figure 17. Polar diagram of yaw wave drift moment: KVLCC2, V = 6 knots.

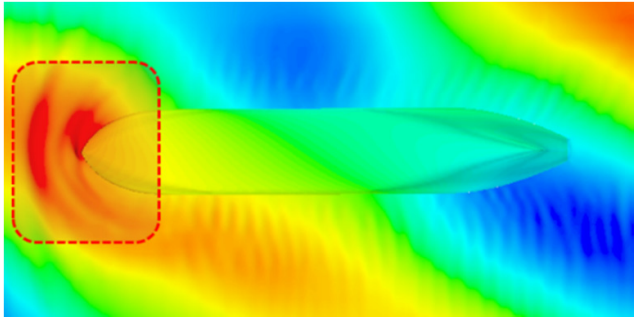

(a) Wave elevation (CFD)

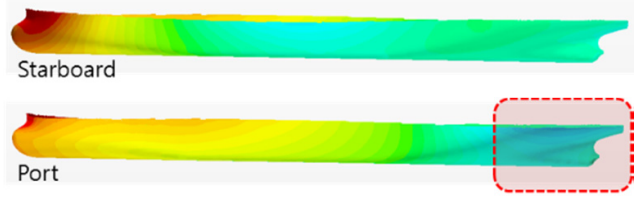

(c) Surface pressure (CFD)

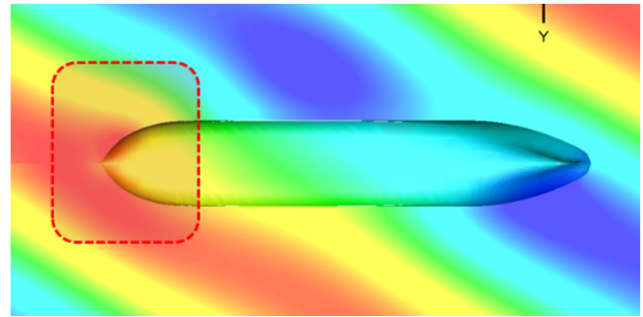

(b) Wave elevation (Potential flow)

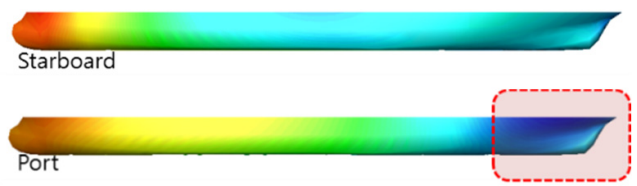

(d) Surface pressure (Potential flow)

Figure 18. Wave elevation and surface pressure on KVLCC2: $V=6$ knots, $\beta=60 \mathrm{deg}, \lambda / L=0.85$.

\section{Conclusions}

In this study, the wave drift force and moment for KVLCC2 with forward speed were estimated using experiment and numerical computation. A captive model test applying a soft spring-type mooring system was conducted in ocean engineering basin in KRISO under various ship speeds and wave conditions. Moreover, numerical analysis was performed using the Rankine panel method based on potential flow, and the wave drift force was estimated using the direct pressure integration method. Based on the present study, the following conclusions can be obtained:

- A measurement system for the wave drift force on a ship sailing with forward speed was successfully designed and developed. An indirect method using tensiometers of soft spring had a relatively significant loss of the measuring value due to the friction of the pulley; therefore, a direct method using force sensors is suitable for accurate measurement of the wave drift force and moment;

- Through a series of model tests, the validation data for the wave drift force are obtained. It was confirmed that potential based computation method could predict the 6-DOF motion with high reliability, and the overall tendency of the wave drift force and moment calculated using the numerical method was very similar to experimental data;

- In the case of the surge drift force calculated by the potential based numerical method, the overall trends were similar, but the magnitude near the short wavelength $(\lambda / L<0.8)$ was smaller than the experimental value. These discrepancies could be improved using the NMRI method. A negative value of the surge drift 
force was found near the stern quartering sea in the experimental data as well as the computational results, which suggests that the ship's total resistance could be decreased when meeting the stern quartering sea;

- The sway wave drift force calculated by the numerical method was almost the same as the experimental value, whereas the yaw wave drift moment showed discrepancies. This meant that the total summations of the second-order pressure on the ship's side surface were similar, but the pressure distribution was different. Notably, the pressure gradient was not adequately applied in the numerical analysis owing to the flow separation in the stern area. Therefore, it is recommended to carefully use the yaw drift moment calculated by the numerical computation based on the potential theory.

Author Contributions: Conceptualization, B.W.N. and Y.K.; methodology, M.G.S. and B.W.N.; software, M.G.S. and Y.J.H.; validation, M.G.S., Y.J.H., and B.W.N.; formal analysis, M.G.S. and B.W.N.; investigation, M.G.S. and B.W.N.; resources, M.G.S. and Y.J.H.; data curation, M.G.S. and B.W.N.; writing-original draft preparation, M.G.S. and B.W.N.; writing-review and editing, Y.J.H. and Y.K.; visualization, M.G.S. and Y.J.H.; supervision, B.W.N. and Y.K.; project administration, Y.K.; funding acquisition, Y.K. All authors have read and agreed to the published version of the manuscript.

Funding: This research was funded by Korea Research Institute of Ships and Ocean Engineering, grant number PES3010 and by the New Faculty Startup Fund from Seoul National University.

Institutional Review Board Statement: Not applicable.

Informed Consent Statement: Not applicable.

Acknowledgments: This research was supported by a grant from Endowment Project of "Development of the analysis technology of ship's integrated ability of maneuvering and seakeeping (PES3010" and "Development of performance evaluation technology for KRISO standard offshore structures in the Deep Ocean Engineering Basin (DOEB) (PES3480)" funded by Korea Research Institute of Ships and Ocean Engineering and by the New Faculty Startup Fund from Seoul National University.

Conflicts of Interest: The authors declare no conflict of interest.

\section{References}

1. Marine Environment Protection Committee. 2013 Guidelines for Calculation of Reference Lines for Use with the Energy Efficiency Design Index (EEDI); MEPC, 2013. Available online: https:/ /scholar.google.com.hk/scholar?cluster=4054065354720390642\&hl= zh-CN\&as_sdt=0,5 (accessed on 28 January 2021).

2. Marine Environment Protection Committee. Interim Guidelines for Degerming Minimum Propulsion Power to Maintain the Manoeuvrability of Ships in Adverse Conditions; MEPC, 2013. Available online: https://www.researchgate.net/publication/31 5642605_2013_INTERIM_GUIDELINES_FOR_DETERMING_MINIMUM_PROPULSION_POWER_TO_MAINTAIN_THE_ MANOEUVRABILITY_OF_SHIPS_IN_ADVERSE_CONDITIONS (accessed on 28 January 2021).

3. Yasukawa, H. Simulations of ship maneuvering in waves (1st report: Turning motion). J. Jpn. Soc. Nav. Archit. Ocean. Eng. 2006, 4, 127-136. [CrossRef]

4. Yasukawa, H.; Zaky, M.; Yonemasu, I.; Miyake, R. Effect of engine output on maneuverability of a VLCC in Still water and adverse weather conditions. J. Mar. Sci. Technol. 2017, 22, 574-586. [CrossRef]

5. Sprenger, F.; Fathi, D. Report on Model Tests at MARINTEK (Trondheim Norway); SHOPERA: Trondheim, Norway, 2015.

6. Maron, A. Report on Model Tests at CEHIPAR (Madrid Spain); SHOPERA: Madrid, Spain, 2015.

7. Kim, D.J.; Yun, K.; Park, J.-Y.; Yeo, D.J.; Kim, Y.G. Experimental investigation on turning characteristics of KVLCC2 tanker in regular waves. Ocean Eng. 2019, 175, 197-206. [CrossRef]

8. Seo, M.-G.; Nam, B.W.; Kim, Y.-G. Numerical evaluation of ship turning performance in regular and irregular waves. J. Offshore Mech. Archit. Eng. 2019, 142, 1-31. [CrossRef]

9. Maruo, H. The drift of a body floating on waves. J. Ship Res. 1960, 4, 1-10.

10. Newman, J.N. The drift force and moment on ships in waves. J. Ship Res. 1967, 11, 51-60. [CrossRef]

11. Faltinsen, O.M.; Minsaas, K.J.; Liapis, N.; Skjørdal, S.O. Prediction of resistance and propulsion of a ship in a seaway. In Proceedings of the 13th Symposium on Naval Hydrodynamics, Tokyo, Japan, 6-8 October 1980; pp. 505-529.

12. Bunnik, T. Seakeeping Calculations for Ships, Taking into Account the Non-Linear Steady Waves. Ph.D. Thesis, Delft University of Technology, Delft, The Netherlands, 22 November 1999.

13. Zhang, S.; Weems, K.M.; Lin, W.-M. Investigation of the horizontal drifting effects on ships with forward speed. In Proceedings of the 28th International Conference on Ocean, Offshore and Arctic Engineering, Honolulu, HI, USA, 31 May-5 June 2018; pp. 433-440. 
14. Joncquez, S.A.G. Second-Order Forces and Moments Acting on Ships in Waves. Ph.D. Thesis, Technical University of Denmark, Copenhagen, Denmark, 2009.

15. Kim, K.H.; Seo, M.G.; Kim, Y. Numerical analysis on added resistance of ships. Int. J. Offshore Polar Eng. 2012, 21, 21-29.

16. Lee, J.-H.; Kim, Y. Study on added resistance of a ship under parametric roll motion. Ocean Eng. 2017, 144, 1-13. [CrossRef]

17. Seo, M.-G.; Kim, Y.; Park, D.-M. Effect of internal sloshing on added resistance of ship. J. Hydrodyn. 2017, 29, 13-26. [CrossRef]

18. Park, D.-M.; Kim, Y.; Seo, M.-G.; Lee, J. Study on added resistance of a tanker in head waves at different drafts. Ocean Eng. 2016, 111, 569-581. [CrossRef]

19. Park, D.-M.; Kim, J.-H.; Kim, Y. Numerical study of added resistance of flexible ship. J. Fluids Struct. 2019, 85, 199-219. [CrossRef]

20. Seo, M.-G.; Yang, K.-K.; Park, D.-M.; Kim, Y. Numerical analysis of added resistance on ships in short waves. Ocean Eng. 2014, 87, 97-110. [CrossRef]

21. Martić, I.; Degiuli, N.; Farkas, A.; Gospić, I. Evaluation of the effect of container ship characteristics on added resistance in waves. J. Mar. Sci. Eng. 2020, 8, 696. [CrossRef]

22. Kuroda, M.; Tsujimoto, M.; Fujiwara, T.; Ohmatsu, S.; Takagi, K. Investigation on components of added resistance in short waves. J. Jpn. Soc. Nav. Archit. Ocean Eng. 2008, 8, 171-176. [CrossRef]

23. Tsujimoto, M.; Shibata, K.; Kuroda, M.; Takagi, K. A practical correction method for added resistance in waves. J. Jpn. Soc. Nav. Archit. Ocean Eng. 2008, 8, 177-184. [CrossRef]

24. Yang, K.-K.; Kashiwagi, M.; Kim, Y. Numerical study on ship-generated unsteady waves based on a cartesian-grid method. J. Hydrodyn. 2020, 32, 953-968. [CrossRef]

25. Kashiwagi, M. Hydrodynamic study on added resistance by means of unsteady wave analysis. J. Jpn. Soc. Nav. Archit. Ocean Eng. 2013, 57. [CrossRef]

26. Liu, S.; Papanikolaou, A. Regression analysis of experimental data for added resistance in waves of arbitrary heading and development of a semi-empirical formula. Ocean Eng. 2020, 206, 107357. [CrossRef]

27. Jinkine, V.; Ferdinande, V. A method for predicting the added resistance of fast cargo ships in head waves. Int. Shipbuild. Prog. 1974, 21, 149-167. [CrossRef]

28. Storm-Tejsen, J.; Yeh, H.Y.H.; Moran, D.D. Added resistance in waves. Trans. Soc. Nav. Archit. Mar. Eng. 1973, 81, $250-279$.

29. Fujii, H.; Takahashi, T. Experimental study on the resistance increase of a large full ship in regular oblique waves. In Proceedings of the 14th International Towing Tank Conference (ITTC1975), Ottawa, ON, Canada, 11 September 1975; pp. 351-360.

30. Nakamura, S.; Naito, S. Propulsive performance of containership in waves. J. Soc. Nav. Archit. Jpn. 1977, 15, 24-48.

31. Guo, B.J.; Steen, S. Evaluation of added resistance of KVLCC2 in short waves. J. Hydrodyn. 2011, 23, 709-722. [CrossRef]

32. Sadat-Hosseini, H.; Wu, P.-C.; Carrica, P.M.; Kim, H.; Toda, Y.; Stern, F. CFD verification and validation of added resistance and motions of KVLCC2 with fixed and free surge in short and long head waves. Ocean Eng. 2013, 59, 240-273. [CrossRef]

33. Park, D.-M.; Lee, J.; Kim, Y. Uncertainty analysis for added resistance experiment of KVLCC2 ship. Ocean Eng. 2015, 95, 143-156. [CrossRef]

34. Lee, J.; Park, D.-M.; Kim, Y. Experimental investigation on the added resistance of modified KVLCC2 hull forms with different bow shapes. Proc. Inst. Mech. Eng. Part M J. Eng. Marit. Environ. 2017, 231, 395-410. [CrossRef]

35. Joncquez, S.A.G. Comparison Results from S-OMEGA and from AEGIR; FORCE Technology: Brøndby, Denmark, 2011.

36. Simonsen, C.D.; Otzen, J.F.; Nielsen, C.; Stern, F. CFD prediction of added resistance of the KCS in regular head and oblique waves. In Proceedings of the 30th Symposium on Naval Hydrodynamics, Hobart, Tasmania, Australia, 2-7 November 2014.

37. Park, D.M.; Lee, J.H.; Jung, Y.W.; Lee, J.; Kim, Y. Comparison of added resistance in oblique seas by numerical analysis and experimental measurement. In Proceedings of the 28th International Ocean and Polar Engineering Conference, Sapporo, Japan, 10-15 June 2018.

38. Nakos, D.E. Ship Wave Patterns and Motions by a Three Dimensional Rankine Panel Method. Ph.D. Thesis, Massachusetts Institute of Technology, Cambridge, MA, USA, June 1990.

39. Seo, M.-G.; Park, D.-M.; Yang, K.-K.; Kim, Y. Comparative study on computation of ship added resistance in waves. Ocean Eng. 2013, 73, 1-15. [CrossRef] 